\title{
RI and PI after R-S recall of overlearned material ${ }^{1,2}$
}

\author{
MARTIN S. LINDAUER \\ STATE UNIVERSITY OF NEW YORK, COLLEGE AT BROCKPORT
}

Retroactive and proactive inhibition (RI and PI) of backward (R-S) associations, following an A-B, A-C paradigm of learning, were investigated. Insuring equivalent availability of the recall items in the control condition, the A-items were overlearned. A backward RI effect was found over three $R-S$ trials; PI was not.

An $\mathbf{R}-\mathrm{S}$ test of the association $\mathrm{B}-\mathrm{A}$, following the $A-B, A-C$ paradigm of learning, involves a procedural difficulty which leads to an underestimation of RI. The experimental condition, in comparison to the control condition which learns A-B only, has an additional exposure during interference learning (IL) to the critical A items later to be recalled. Extinction or unlearning may be masked by the greater availability of the A items, a factor which increases the probability of successful guessing during the recall test and hence an absence of backward RI (Keppel \& Underwood, 1962). This disadvantage in the control condition has been compensated for, and RI has been found, by using A items already highly available because they are familiar (Houston, 1964b), or by using materials, instructions, and procedures which increase response availability (Houston, 1964a; Horowitz, Brown, \& Weissbluth, 1964; Birnbaum, 1966). However, despite the equivalent availability of the critical items in both control and RI conditions, the latter receives an extra exposure to these ttems during IL which may still inflate $\mathrm{RI}$ recall scores. In the present experiment, in addition to using highly available $A$ items, they were also overlearned prior to paired associate learning. This insures that the additional exposure in the RI condition will have a relatively small effect on the learning of the A Items. In addition, backward PI under these conditions of overlearning was also investigated. Method

Three groups of Ss learned an A-B list of 10 paired associates (OL). Two groups learned as IL an A-C list either before or after OL (the PI and RI conditions, respectively). Two lists of unrelated two syllable adjectives, randomly drawn from Hilgard (1951, pp. 548-552) were used. One list was always used as OL, the other as IL. Three orders of presentation were prepared for each list and randomly assigned to each $S$, except that the starting order at recall was different from the last order used during OL. Ss were 48 female undergraduate volunteers assigned to three equal groups of $16 \mathrm{Ss}$ each on the basis of their performance on the stimulus overlearning session. None had previously served in a verbal learning experiment.
Prior to learning any list, all Ss first overlearned the stimulus items common to both lists, which were later to be recalled in an R-S test. The A items were presented for 4 sec each until all 10 had been exposed. Following this, S was allowed $30 \mathrm{sec}$ for the free recall of these items in any order. This procedure continued until $S$ achieved a criterion of two errorless free recall tests in succession. When stimulus learning was completed, Ss were matched on the basis of their performance on this task for assignment to the three groups, and began paired associate learning. OL was learned to a criterion of one errorless trial; IL was presented for 10 trials. The two lists followed each other directly, with only a $15 \mathrm{sec}$ interruption to give instructions for the second list. The Control group learned only OL to the same criterion as the RI and PI groups. The lists were presented on a Hull-type memory drum at a 2:2 rate, with an 8 sec intertrial interval. For all groups, there was a retention interval of $30 \mathrm{~min}$ between the end of OL and the beginning of the recall period. During the rest period $(30 \mathrm{~min}$ for the Control and PI groups, $22.5 \mathrm{~min}$ for the RI group), $\mathrm{S}$ was asked to inspect and rate cartoons. Following the rest interval, $S$ was tested for $R-S$ recall of $O L$. Using the method of anticipation and the same time intervals as those employed during $\mathrm{OL}, \mathrm{S}$ was presented with the response term (now located in the position previously occupied by the stimulus term) and was asked to anticipate the previously learned stimulus term. The first recall trial was followed by two relearning (RL) trials.

Results

The mean number of trials required to learn the stimulus items was $8.6,8.3$, and 8.5 for Groups Control, RI, and PI, respectively. The corresponding figures for the mean number of trials required to learn OL were 15.0, 15.5, and 13.3. The differences between the groups in both learning situations were not significant $(F<1)$. The mean number of correct anticipations on the last (tenth) trial of IL was 7.6 for the RI group and 7.4 for the PI group; this difference was not significant $(t<1,00)$. Figure 1 presents the mean number of items recalled correctly on the three R-S test trials. As indicated, recall was best for Group PI and worst for Group RI. Analysis of variance of these three recall trials yielded a significant effect for groups $(F=3.72, d f=2 / 45, p<.05)$, which did not change over the three test trials, since there was no significant interaction of groups by trials $(F=1.24$, $\mathrm{df}=4 / 143, \mathrm{p}>.05)$; there was a significant effect for 


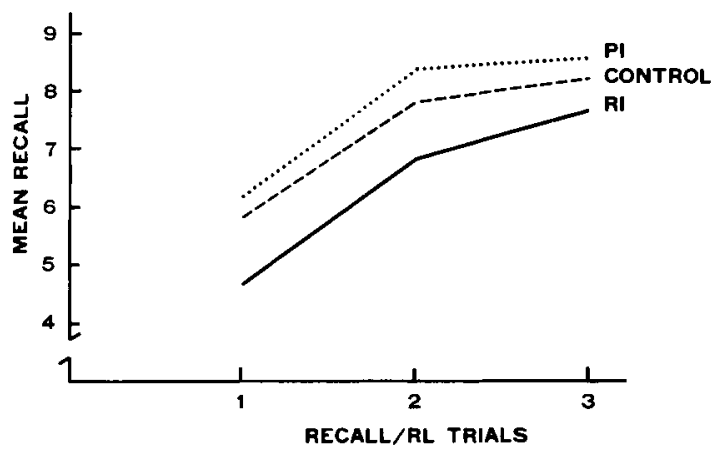

Fig. 1. Mean number correctly recalled and relearned (RL) in three R-S test trials.

trials $(F=109.20, d f=2 / 143, p<.01)$. The difference between Groups Control and RI was significant $(t=2.43$, $\mathrm{df}=30, \mathrm{p}<.02)$, as was the difference between Groups $R I$ and $P I(t=3.82, d f=30, p<.01)$. On the other hand, the difference between Groups Control and PI was not significant $(t=1.39, \mathrm{df}=30, p>.05)$.

Discussion

In keeping with the findings of most studies in this area, RI of backward associations was found after $A-B, A-C$ learning when response availability was assured. In the present study this was accomplished through the use of highly familiar material which was also overlearned. This also resulted in the persistence of the RI effect over three test trials. Consequently, there is additional support for the bidirectionality of learning and unlearning processes. In addition, although RI was greater than PI, the lack of a PI effect is not in keeping with a two factor theory of forgetting (Postman, 1961) as it might apply to backward associations. Evidently, response competition at recall is nullified under the conditions of this experiment, leaving only unlearning responsible for a decrement in backward recall. Hence, RI but no PI, since $\mathrm{RI}$ is a result of both unlearning and response competition, while PI is a function of the latter only.

\section{References}

BIRNBAUM, I. M. Unlearning in two directions. J. exp. Psychol, 1966, 72, 61-67.

HILGARD, E. R. Methods and procedures in the study of learning. In S. S. Stevens (Ed.), Handbook of experimental psychology. New York: Wiley, 1951.

HOROWITZ, L. M., BROWN, Z. M., \& WEISSBLUTH, S. Availability and the direction of associations. J. exp. Psychol, 1964, 68, 541-549.

HOUSTON, J. P. S-R stimulus selection and strength of R-S associations. J. exp. Psychol, 1964a, 68, 563-566.

HOUSTON, J. P. Verbal R-S strength following S-R extinction. Psychon. Sci. 1964b, 1, 173-174.

KEPPEL, G., \& UNDERWOOD, B. J. Retroactive inhibition of R-S associations. J. exp. Psychol, 1962, 64, 400-404.

POSTMAN, L. The present status of interference theory. In C.N. Cofer (Ed.), Verbal learning and verbal behavior. New York: McGraw-Hill, 1961.

\section{Notes}

1. Data were collected at Cedar Crest College.

2. Dr. H. Gleitman provided valuable assistance on earlier versions of this manuscript. 